\title{
The impact of physical fitness on resilience to modern life stress and the mediating role of general self-efficacy
}

\author{
R. J. Neumann ${ }^{1}$ (1) - K. F. Ahrens ${ }^{1}$ - B. Kollmann ${ }^{2,3} \cdot$ N. Goldbach ${ }^{1} \cdot$ A. Chmitorz ${ }^{4}$ - D. Weichert ${ }^{2,3} \cdot$ C. J. Fiebach ${ }^{5,6}$.

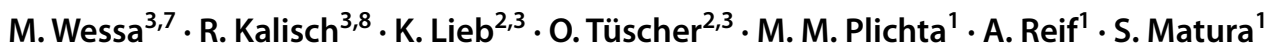

Received: 25 June 2021 / Accepted: 22 September 2021 / Published online: 7 October 2021

(c) The Author(s) 2021

\begin{abstract}
Substantial evidence shows that physical activity and fitness play a protective role in the development of stress related disorders. However, the beneficial effects of fitness for resilience to modern life stress are not fully understood. Potentially protective effects may be attributed to enhanced resilience via underlying psychosocial mechanisms such as self-efficacy expectations. This study investigated whether physical activity and fitness contribute to prospectively measured resilience and examined the mediating effect of general self-efficacy. 431 initially healthy adults participated in fitness assessments as part of a longitudinal-prospective study, designed to identify mechanisms of resilience. Self-efficacy and habitual activity were assessed in parallel to cardiorespiratory and muscular fitness, which were determined by a submaximal step-test, hand strength and standing long jump test. Resilience was indexed by stressor reactivity: mental health problems in relation to reported life events and daily hassles, monitored quarterly for nine months. Hierarchical linear regression models and bootstrapped mediation analyses were applied. We could show that muscular and self-perceived fitness were positively associated with stress resilience. Extending this finding, the muscular fitness-resilience relationship was partly mediated by self-efficacy expectations. In this context, self-efficacy expectations may act as one underlying psychological mechanism, with complementary benefits for the promotion of mental health. While physical activity and cardiorespiratory fitness did not predict resilience prospectively, we found muscular and self-perceived fitness to be significant prognostic parameters for stress resilience. Although there is still more need to identify specific fitness parameters in light of stress resilience, our study underscores the general relevance of fitness for stress-related disorders prevention.
\end{abstract}

Keywords Physical fitness $\cdot$ Physical activity $\cdot$ Stress resilience $\cdot$ Mental health disorders $\cdot$ Self-efficacy

R. J. Neumann

rebecca.neumann@kgu.de

1 Department of Psychiatry, Psychosomatic Medicine and Psychotherapy, University Hospital Frankfurt, GoetheUniversity, Heinrich-Hoffmann-Str. 10, 60528 Frankfurt/ Main, Germany

2 Department of Psychiatry and Psychotherapy, University Medical Center Mainz, Mainz, Germany

3 Leibniz Institute for Resilience Research (LIR) gGmbH, Mainz, Germany

4 Faculty of Social Work, Education and Nursing Sciences, Esslingen University of Applied Sciences, Esslingen, Germany
5 Department of Psychology, Goethe University, Frankfurt, Frankfurt am Main, Germany

6 Brain Imaging Center, Goethe University, Frankfurt am Main, Germany

7 Department of Clinical Psychology and Neuropsychology, Institute for Psychology, Johannes Gutenberg University Mainz, Mainz, Germany

8 Neuroimaging Center (NIC), Focus Program Translational Neuroscience (FTN), University Medical Center Mainz, Mainz, Germany 


\section{Introduction}

Being physically inactive ranks among the most important public health problems in modern days, as it has been found to be the fourth-leading risk factor of death worldwide and is associated with increased incidence of mental disorders [1-4]. While prevalence of stress-related mental disorders continues to rise, $25 \%$ of European adults are estimated to be insufficiently active which did not change over the past decade [2]. These statistics are startling, given the comprehensive evidence for the potential mental and physical health benefits of physical activity and fitness.

\section{Physical activity, fitness and mental health}

The direct associations between physical activity, physical fitness and mental health are well established. Physically active individuals report better emotional well-being [5] and mood enhancement [6]. Especially, physical activity has been suggested as a protective factor against the development of common stress related mental health problems. A large number of clinical, interventional and epidemiological prospective studies have demonstrated a dosedependent effect of regular exercise or habitual physical activity on depression and anxiety [7-12]. Also physical fitness, which may result from the interplay of different factors such as exercise participation, but may also in part be genetically determined [13], has been recognised as an important marker of mental health [14, 15]. Among different health-related fitness components, cardiorespiratory fitness (CRF) has most frequently been associated with lower rates of stress related mental health problems such as depression and burnout [16-19]. In a recent meta-analysis of prospective cohort studies Kandola et al. [20] suggested a dose-response relationship between CRF and the risk of common mental health disorders. Although less wellestablished than $\mathrm{CRF}$, muscular fitness has increasingly been recognised as an important physical parameter. Muscular strength has been positively associated with mental resources, health-related quality of life in adolescents and aged people [14, 21], and inversely associated with the development of depressive symptoms and frailty [22-24]. While Kettunen et al. [21] concluded that both, cardiorespiratory and muscular fitness are associated with mental resources in men, the additional value of muscular fitness remains unclarified. Åvitsland et al. [25] indicated that muscular fitness is independently associated with mental health problems, however, when controlling for CRF, the effect vanished. Nonetheless, as recently suggested by Tacci et al. [17], objective fitness measurements and the onset of mental health problems are an emerging field. Based on the lack of methodological comparable investigations and data on both, activity levels and objective fitness measures, there is a substantial need for population-based studies focussing on the association between fitness components and future risk of adverse mental health outcomes.

\section{Physical activity and fitness as stress-buffers and resilience factors}

While the direct relationship between physical activity, fitness and common mental health disorders has been widely recognised, the amount of stress individuals are facing is rarely considered. In resilience research the focus lies on preventive factors and mechanisms that have the potential to mitigate undesirable consequences of stress and promote mental health in the face of stressor exposure. Lately resilience has increasingly been conceptualised as the outcome of a dynamic process of adaptation in the face of adversity and changing demands [26-28]. Thus individuals with high resilience are less likely to develop mental health problems than expected in proportion to the accumulated stressor load [29]. A few cross-sectional and longitudinal field studies addressed the protective, stress-buffering effects of exercise and fitness, which have both been associated with a better capacity to cope with chronic stress, less health-complaints, and higher self-perceived resilience [18, 21, 30-32]. Interestingly, according to Klaperski, Seelig, and Fuchs [33], in longitudinal analyses, chronic exercise participation was capable to buffer moderate intense chronic stress. But the authors found no evidence for this stress-buffering function of physical activity against the effects of acute stress in the cross sectional design. A recent study by Schilling et al. [34] addressed the potential stress buffering effect of CRF in a real-life study on police officers and indicated lowered physiological stress reactivity to acute work stress in police officers with higher levels of CRF. Still, the literature offers insufficient evidence concerning the protective role of physical fitness to everyday life stressor exposure or modern life stress, including daily hassles and life events.

\section{Psychological mechanism: general self-efficacy}

Insight into the mediating pathways is essential to understand the mechanisms underlying the beneficial effects of physical fitness on stress coping. With regard to cognitive appraisal, the concept of self-efficacy, as initially introduced by Bandura's social cognitive theory, refers to the belief of one's capabilities to perform properly in challenging situations [35-37]. It has been proposed as a resistance resource within the cognitive appraisal process, which is known to be crucial for the regulation of stressful, potentially traumatising demands $[38,39]$. The stress regulatory capacities are 
used as a possible explanation in research proposing that efficacy expectations buffer the negative effects of daily stress or life events on mental health problems [40-44]. More recently, self-efficacy has also been postulated as an essential resilience mechanism in the positive appraisal style theory of resilience (PASTOR) [45]. Earlier theoretical models state that changes in physical activity and fitness can act as a mastery or efficacy experience in the physical domain $[46,47]$. This experience may even generalise to a broader physical self-concept and, consequently, to enhanced global self-esteem and psychological wellbeing. Interestingly, selfefficacy has been shown to be both, a determinant as well as a consequence of physical activity [47]. Nonetheless, to our knowledge, the mediating effect of self-efficacy on the relation between physical activity and fitness on resilience to stress has not systematically been examined yet. This study is motivated by the hypothesis that physical activity and fitness alter stress perceptions, i.e., the way we interpret stressful situations, and by this play a crucial role in coping with everyday stress.

\section{Study aims}

Our primary aim is to extend earlier findings of a "stressbuffering effect" of activity and fitness, and to examine, whether health-related fitness components CRF, muscular strength, self-perceived fitness and physical activity predict mental health outcomes in the face of modern life stress, hence resilience to stress. Our second objective is to investigate whether the effects of physical fitness and activity on resilience are mediated by self-efficacy as a cognitive mechanism. We postulate that self-efficacy partly explains the relation between physical activity, fitness and resilience to stress. To investigate the association between physical fitness, self-efficacy and resilience we analyse a sub-sample from the $L O$ ngitudinal Resilience Assessment (LORA) study, - a longitudinal prospective study to identify various mechanisms of resilience.

\section{Method}

\section{Study design and participants}

The LORA study is a population-based, multi-center cohort study. Data collection for baseline assessment at the study sites Frankfurt and Mainz started in 2017 and continued until 2019. Planned longitudinal assessment will be ongoing for at least 4.5 years [48]. Participants from the Rhine-Main Area were recruited via online or printed public advertisements at the local universities, medical centres, libraries, shops and gyms and the projects webpage (https://lorastudie.de/). After agreement to study participation, study eligibility was tested via a structured telephone interview. The inclusion criteria were age 18 to 50 years, having normal or corrected vision and sufficient knowledge of the German language. The exclusion criteria were lifetime diagnosis of schizophrenia or bipolar disorder, organic mental disorders or substance dependence syndromes, as well as any other current severe axis-I disorder or medical conditions. Participants with known learning disabilities, serious neurological disorders (e. g., tumours in the central nervous system), or participants who had taken part in a drug trial in the previous six months were also excluded.

In total, 1191 healthy were enrolled, of which 472 subjects fully completed a fitness test at baseline assessment (T0). After participants were found eligible, they were invited for an extensive baseline assessment (T0), where they received further detailed information about study participation and were asked to give informed consent. A clinical interview and anthropometric and fitness measures were conducted. After the in-house assessment participants were introduced to the online database system (secuTrial $\odot$ electronic data capture system, www.secutrial.com), which adheres to the Guidelines for Good Clinical Practice (GCP). Herein participants were asked to complete the questionnaires on socio-demographics, mental health, life history, psychological, and lifestyle-related variables including proposed resilience factors within a week following the visit. For longitudinal assessment of mental health and stressor exposure, an interim online stressor monitoring was applied every three months, using the same online data base system. In this study, relevant fitness and health measurements at baseline (T0; Fig. 1a) and stressor monitoring of the first nine months (T1-T3; Fig. 1b) were evaluated. Figure 1 displays the adapted study design.

\section{Instruments}

Physical fitness at baseline (Fig. 1a) was assessed according to the standard procedures and recommendations for assessing physical activity levels at population level (ALPHA [49]).

Cardiorespiratory fitness (CRF) was measured by the Chester Step Test (CST) to predict maximal oxygen uptake (VO2max) [50]. The CST is a sub-maximal, multistage test, where the participants step on and of a 30-cm step on timed metronome rhythms. For a detailed description of the Chester Step Test see Sykes [50]. For reference, average aerobic capacity $(\mathrm{mlsO} / \mathrm{kg} / \mathrm{min})$ for women between 20 and 29 years are $35-43 \mathrm{mls} 02 \mathrm{~kg} / \mathrm{min}$ and for men in the same age range $32-38 \mathrm{mls} 02 \mathrm{~kg} / \mathrm{min}$ [50].

A composite measure for muscular fitness/strength was built upon handgrip strength (representative for upper body isometric strength) and a standing long jump (representative for lower body strength). Maximum handgrip strength 


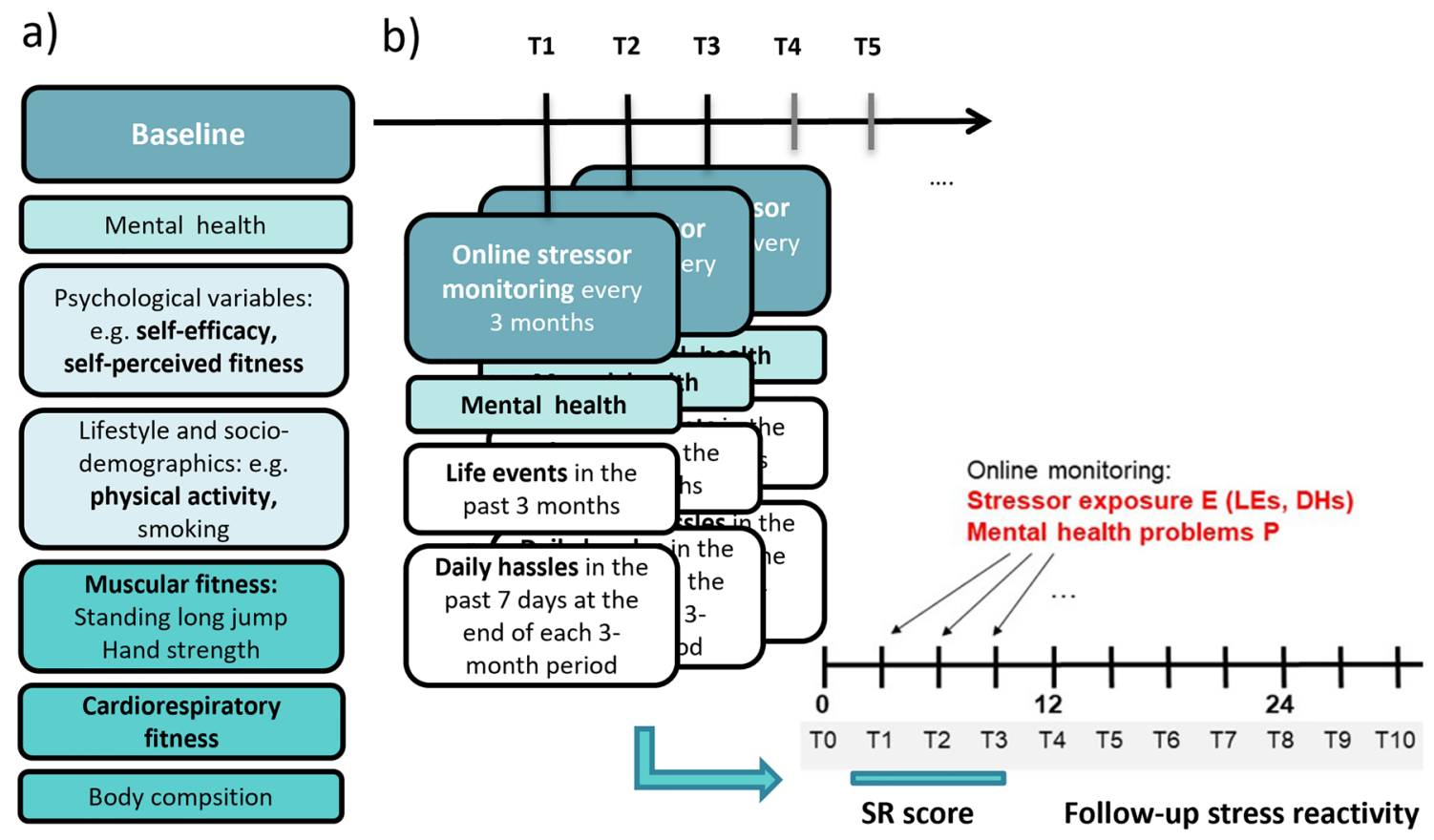

Fig. 1 Adapted LORA study design from Chmitorz et al., [48] with a selected baseline measurements: Physical fitness components, physical activity, self-perceived fitness and general-self efficacy and $\mathbf{b}$ the

[51] is a widely used test for assessing muscular fitness in adults and was measured by using a handgrip dynamometer (T.K.K.5001, Grip-A; Takei, Japan). For the assessment, participants were asked to stand with their extended arms by their side and, on command, squeeze the handgrip continuously as hard as possible. To determine the full potential of handgrip strength, the optimal grip-span of the dynamometer was accustomed according to sex and hand size. Alternating between left and right hand the test was performed twice per hand. The maximum score for each hand, expressed in $\mathrm{kg}$, was recorded and the highest score for the stronger hand was used for the analyses [52]. Whereas, norms highly depend on age, sex or the instrument used, earlier studies found mean values of $39.1 \pm 12.8 \mathrm{~kg}$ among healthy adults across the life span [53, 54]. Furthermore, for the assessment of lower body explosive muscular strength, the participants completed a standing long jump [55]. Therefore, they were instructed to jump from a starting line, to push off vigorously and to jump as far as possible. Participants had to land on both feet and stay upright. Then the distance between the first heel-mark and the take-off-line was recorded in centimeters and the best attempt was considered for muscular strength measurement $[14,56]$.

Self-perceived fitness was assessed using the International fitness scale (IFIS [57]), developed by the PROFITH research group, Granada, Spain, to rate participants according to their overall physical fitness by the main physical fitness components. The IFIS is a self-reporting questionnaire follow-up interim stressor-monitorings in 3-months intervals. Followup measurements are used to build up the stressor reactivity score (SR score) as an outcome

composed of five questions on participants' perceived physical fitness: cardiorespiratory fitness, muscular fitness, speed-agility, flexibility and overall fitness in comparison with others' physical fitness. For an overall perceived fitness rating, all five questions were summed up to one fitness score.

The International physical activity questionnaire (IPAQ [58]) was used to assess four dimensions of physical activity: occupation, transportation, household activities, and leisuretime, as well as sedentary behaviour in a typical week. The self-report questionnaire asked participants to recall activities for each of the seven preceding days that measure the time spent engaged in walking, moderate activity (e.g., carrying light loads, bicycling or easy swimming), vigorous intensity activity (hard physical effort e.g., lifting, aerobics, fast running) and sedentary behaviour. The sum of weekly metabolic equivalent (MET)-minutes per week was used as a continuous activity indicator of the four categories. For analyses the weighted MET-minutes per week were summed up across walking, moderate and vigorous intensity activities to produce a weighted estimate of total physical activity per week. The IPAQ is a valid and reliable surveillance tool to monitor physical activity levels [59]. High levels of physical activity are characterised by at least 3000 MET minutes per week [60].

For anthropometric measures weight was taken using a calibrated electronic scale (Seca, Birmingham, UK) with an accuracy of $0.1 \mathrm{~kg}$ and height with a stadiometer (Seca) 
with an accuracy of $0.1 \mathrm{~cm}$. Body Mass Index (BMI) was calculated in $\mathrm{kg} / \mathrm{height}$ in $\mathrm{m}^{2}$.

The General Self-Efficacy Scale (GSE; [61, 62]) was applied to measure an estimate of general perceived self-efficacy across 10 items, which were rated on a 4-point Likertscale (from 'not at all true' to 'exactly true'). The GSE covers judgments concerning causal and control beliefs, such as the extent to which one attributes the successful handling of difficult situations to one's own competence.

Resilience to stress, as displayed in Fig. 1b, is operationalized as mental health status corrected for stressor exposure, which indicates individual reactivity of mental health to stressors: stressor reactivity score (SR score). Participants were asked to report on their experienced stressor exposure every three months over a nine-month period, including macro-stressors (critical life events) and micro-stressors (daily hassles). Exposure to critical life events was collected retrospectively, using an adapted German version of a standard life events (LE) checklist from Canli et al. [63] The questionnaire lists critical or major life events and incidents of potentially traumatising events. The adapted German version contains 27 items, for which participants indicated whether the respective event occurred within the previous three months. For a life event sum score, occurrences of events were summed up. Regarding micro-stressors, chronic stressors and daily hassles (DH) were assessed using the Mainz Inventory of Microstressors (MIMIS), which was recently developed and validated by Chmitorz et al. [64]. Here, participants are asked to retrospectively report the number of days the stressors occurred from a list of $58 \mathrm{DH}$ (ranging from 1 to 7 days) within the past seven days, including the day of assessment. For analyses, DH were calculated by multiplying the total amount of all hassles reported in the past week with the reported number of days on which a hassle occurred (range $0-58 \times 7$ days $=406$ ). For the assessment of general health status, the German version of the General Health Questionaire-28 (GHQ-28; [65, 66]) was used. The GHQ-28 is a 28 -item measure of emotional distress and rates participant's subjectively reported health over the last couple of weeks on a four-point Likert scale ranging from 0 (least symptomatic answer) to 3 (most symptomatic answer) with the possible total score ranging from 0 to 84 . Goldberg (1978 [65]) suggests a threshold for psychiatric distress of a total sum score of 23/24. Items are assessed on four scales, i.e., somatic symptoms, anxiety/sleeplessness, social dysfunction, and severe depressive symptoms.

\section{Statistical analysis}

For all statistical analyses IBM SPSS Statistics version 25 for Windows (Armonk, NY, USA) was used. Prior to analyses raw data was tested for normality distribution of residuals, errors, plausibility, excessive missing cases, outliers and studentized deleted residuals, resulting in $N=431$ cases being included into statistical analyses. Spearman's rank correlations were performed to reveal the differences in mean demographics (sex, age, BMI, income, education level) and independent variables (IV). Accordingly, covariates were included in the analysis.

For the quantification of resilience as an outcome, in accordance with Kalisch et al. [29], we used a residualization-based calculation of stressor reactivity (SR score) during a timeframe of nine months (T1-T3, Fig. 1b.). The SR score was used as the outcome variable for hypothesis testing. Participants of the full study sample, who provided a minimum of one complete 3 -monthly monitoring, were included in the analysis $(N=1078)$. A high SR score implies low resilience and high stressor reactivity, meaning more mental health problems in proportion to the stressor load. A low SR score indicates high resilience and low stressor reactivity, thus relatively low-mental health problems in response to stress.

Before main analyses, all fitness components were transformed into standardised values (Z-scores) to relate them to relative fitness levels. $Z$-scores for the standing long jump and hand strength were combined to a composite mean score for muscular strength.

For main hypotheses testing a hierarchical multiple regression model was conducted to examine whether physical fitness and activity (independent predictor variables) predict stress reactivity over a 9-months timeframe (dependent variable). Sex, age and BMI were entered at stage one of the regression to control for these influencing variables. Physical fitness and activity were entered at stage two with forced entry to determine the true correlation between fitness and stress reactivity controlling for the effect of potential influencing factors.

To test whether the association between the fitness components and stress reactivity was mediated by general self-efficacy, mediation analyses were performed using the PROCESS macro by Hayes [67]. Unstandardized path coefficients for total, direct, and indirect effects were estimated by means of ordinary least squares (OLS) regression analyses. Sex, age and BMI were entered as covariates. Bootstrapping with 5000 samples together with heteroscedasticity consistent standard errors [68] were fitted to compute the confidence intervals and inferential statistics. Effects were deemed significant when the confidence interval did not include zero. The coefficients (a, $\mathrm{b}$ and $\mathrm{c}^{\prime}$ ) represent the fully standardised regression coefficients. A $p$ value of 0.05 (two-tailed) or smaller determines statistical significance. 


\section{Results}

\section{Participant characteristics, correlations, and stress reactivity calculation}

Descriptive statistics for all relevant variables over the whole sample, consisting of 431 participants with complete data for fitness measures, are displayed in Table 1. GHQ mean score significantly increased (i.e., average mental health worsened) from the baseline assessment $16.33( \pm 7.54)$ to an average of $20.51( \pm 7.70)$ over the nine months (T1-T3). Quantification of stressor reactivity score (SR score; based on linear regression modelling across T1 to T3) indicated a significant linear positive relationship between combined stressor exposure and mental health problems $(R=0.41, p<0.001, N=1078)$.

Table 2 depicts the partial intercorrelations of all tested variables, controlled for relevant covariates sex, age and BMI. GHQ at baseline was included as control variable. The main outcome, stressor reactivity over T1 to T3, where a lower value reflects greater resilience to stress, was negatively related to baseline (T0) muscular strength and self-perceived fitness.

Table 1 Participants' sociodemographic and anthropometric characteristics and tested variables

\begin{tabular}{|c|c|c|}
\hline & Total sample mean \pm SD / frequency & Range \\
\hline Age & $27.15 \pm 6.85$ & $18-50$ \\
\hline \multicolumn{3}{|l|}{ Sex } \\
\hline 운 & $274(63.6 \%)$ & \\
\hline$\hat{0}$ & $157(36.4 \%)$ & \\
\hline \multicolumn{3}{|l|}{ Highest educational achievement (T0) } \\
\hline School-leaving certificate & $1(0.2 \%)$ & \\
\hline Certificate of Secondary Education & $8(1.9 \%)$ & \\
\hline School leaving examination & $188(44.3 \%)$ & \\
\hline Completed vocational training & $53(12.5 \%)$ & \\
\hline University degree & $176(41.0 \%)$ & \\
\hline \multicolumn{3}{|l|}{ Employment (T0) } \\
\hline Full-time & $109(25.8 \%)$ & \\
\hline Part-time & $42(9.9 \%)$ & \\
\hline No employment & $10(2.3 \%)$ & \\
\hline Currently obtaining an education & $262(61.9 \%)$ & \\
\hline \multicolumn{3}{|l|}{ Marital status (T0) } \\
\hline Non-married & $359(85.1 \%)$ & \\
\hline Married & $59(14.0 \%)$ & \\
\hline Separated/divorced & $4(0.9 \%)$ & \\
\hline Smoking (yes; no) (T0) & $46(10.7 \%) ; 385(89.3 \%)$ & \\
\hline Body mass index (BMI) (T0) & $23.29 \pm 3.39$ & \\
\hline Handgrip strength (kg) (T0) & $35.85 \pm 10.63$ & $0-100$ \\
\hline Standing long jump (cm) (T0) & $162.69 \pm 34.05$ & \\
\hline Aerobic capacity Vo2max (O2/kg/min) (T0) & $46.71 \pm 10.41$ & \\
\hline Total physical activity (MET) per week (IPAQ) (T0) & $4269.09 \pm 3011.82$ & \\
\hline Self-perceived fitness (IFIS) (T0) & $18.34 \pm 3.06$ & $0-25$ \\
\hline General self-efficacy (GSE) (T0) & $30.13 \pm 4.02$ & $0-40$ \\
\hline GHQ-28 baseline (T0) & $16.41 \pm 7.54$ & $0-84 ;$ cut off $23 / 24$ \\
\hline GHQ-28 (mean T1-T3) & $20.51 \pm 7.70$ & $0-84$ \\
\hline Number of Life Events (past 9 months, mean T1-T3) & $2.01 \pm 1.36$ & $0-27$ \\
\hline Number of Daily Hassles (per week, mean T1-T3) & $61.44 \pm 25.22$ & $0-58 \times 7$ days $=406$ \\
\hline
\end{tabular}

$N=431$

T0 indicate the baseline data

T1-T3 portray the follow-up data which are used to calculate the SR score, including mental health problems and stressors within the upcoming 9 months

Percentage based on valid data; mean and standard deviation based on all obtained data. 
Table 2 Intercorrelations of all tested variables

\begin{tabular}{llllllll}
\hline Variable & SR & PA & CRF & MS & SPF & GHQ-28 & GSE \\
\hline SR score (T1-T3) & & & & & & \\
PA & -0.03 & & & & & \\
CRF & -0.02 & $0.18^{* *}$ & & & & \\
MS & $-0.15^{*}$ & 0.03 & 0.11 & & & \\
SPF & $-0.19 * *$ & $0.26 * * *$ & $0.29 * * *$ & $0.35^{* * *}$ & & \\
GHQ-28 & $0.32^{* * *}$ & 0.04 & 0.03 & -0.07 & $-0.17 * *$ & \\
GSE & -0.14 & 0.05 & -0.07 & 0.13 & $0.22^{* * *}$ & $-0.26^{* * *}$ & \\
\hline
\end{tabular}

$S R$ score stressor reactivity across $\mathrm{T} 1-\mathrm{T} 3$, baseline variables: $P A$ physical activity, $C R F$ cardiorespiratory fitness, $M S$ muscular strength, $S P F$ self-perceived fitness, GHQ-28 General Health Questionnaire, GSE general self-efficacy

$N=431$

Bonferoni-Holm corrected partial correlations controlled for sex, age, BMI are presented; adjusted $p$ values due to Bonferroni-Holm method $* p<0.05$, ** $p<0.01$, *** $p<0.001$.

\begin{tabular}{|c|c|c|c|c|c|}
\hline Variable & $\mathrm{B}(95 \% \mathrm{Cl})$ & $\beta$ & $t$ & $\Delta R^{2}$ & $p$ value \\
\hline Step 1 & & & & 0.029 & $<0.01$ \\
\hline Sex & $0.32[-0.13,0.51]$ & 0.17 & 3.28 & & 0.001 \\
\hline Age & $-0.12[-0.23,0.18]$ & -0.12 & -2.31 & & 0.02 \\
\hline BMI & $0.09[-0.03,0.21]$ & 0.08 & 1.40 & & 0.16 \\
\hline Step 2 & & & & 0.062 & $<0.01$ \\
\hline Sex & $0.08[-0.20,0.35]$ & 0.04 & 0.54 & & 0.59 \\
\hline Age & $-0.13[-0.24,-0.03]$ & -0.12 & -2.44 & & 0.02 \\
\hline BMI & $0.07[-0.05,0.19]$ & 0.06 & 1.10 & & 0.27 \\
\hline Muscular strength & $-0.14[-0.28,-0.04]$ & -0.16 & -2.02 & & 0.04 \\
\hline Self-perceived fitness & $-0.15[-0.25,-0.05]$ & -0.15 & -2.94 & & $<0.01$ \\
\hline $\mathrm{CRF}$ & $0.04[-0.48,0.13]$ & 0.05 & 0.20 & & 0.36 \\
\hline Physical activity & $0.01[-0.09,0.11]$ & 0.01 & 0.27 & & 0.79 \\
\hline
\end{tabular}

$N=431$

95\% bias corrected and accelerated confidence intervals reported in parentheses.
Table 3 Summary of hierarchical regression analysis with Stressor reactivity (SR) score as dependent variable

\section{Predicting resilience from activity and fitness}

The two-stage hierarchical regression model with stressor reactivity as the dependent variable is shown in Table 3. Relevant covariates (sex, age, BMI) were entered at stage one of the regression analysis to control for confounding demographic effects. The four baseline variables for activity and fitness were simultaneously entered at stage two. The results revealed that at stage one the demographic variables contributed significantly to the regression model, $F(3$, $427)=5.26, p=0.001$ and accounted for $2.9 \%$ of the variation in stressor reactivity, with sex and age being significant. Introducing the four additional independent fitness variables at stage two, accounted significantly for $6.2 \%$ of the variation of stressor reactivity, $F(4,423)=5.10, p=0.001$. Muscular strength $(B=-0.14, p=<0.01,95 \%$ CI $[-0.28,-0.04])$ and self-perceived fitness $(B=-0.15, p=0.01,95 \% \mathrm{CI}$ $[-0.25,-0.05])$ were both significantly negatively related to stressor reactivity. However, neither CRF nor physical activity score were significant predictors of stressor reactivity. Our results suggest that higher muscular strength and higher self-perceived fitness are significantly related with higher resilience to stress.

\section{Mediation by self-efficacy on resilience to stress}

Two simple bootstrapped mediations analyses were performed to examine whether the direct paths between muscular fitness (mediation model 1) or self-perceived fitness (mediation model 2) and stressor reactivity would be mediated by general self-efficacy. Within the first mediation model all regression coefficients were statistically significant (see Fig. 2). In accordance with primary regressions, the direct, inverse effect of muscular strength on stressor reactivity remained significant, path c': $b=-0.19$, $p=0.004,95 \%$ CI $[-0.32,-0.06]$. Entering the mediator into the model resulted in muscular strength being a significant predictor for general self-efficacy, path a: $b=0.19$, 


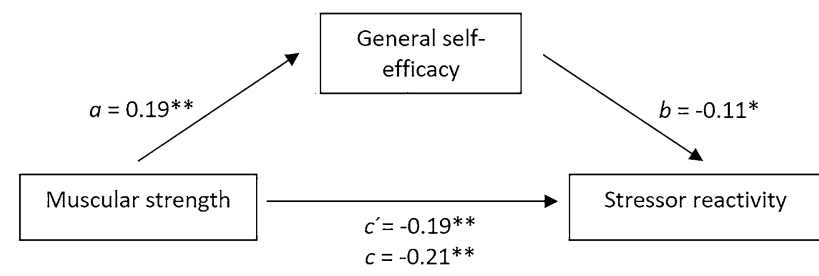

Fig. 2 Conceptual and statistical diagram of the mediation model for the direct and indirect effects of muscular strength on stress reactivity. Regression coefficients (fully standardised): a effect of muscular strength on general self-efficacy, $\mathbf{b}$ effect of general self-efficacy on stressor reactivity, c' direct effect of muscular strength on stressor reactivity, $\mathbf{c}$ total effect of muscular strength, general self-efficacy on stressor reactivity. ${ }^{* *} p<0.01 .{ }^{*} p<0.05$

$p=0.009,95 \%$ CI $[0.04,0.34]$, which in turn significantly predicted stressor reactivity, path $\mathrm{b}: b=-0.11, p=0.014$, $95 \%$ CI $[-0.20,-0.02]$. The results show that the relationship between muscular strength and stressor reactivity was partially mediated by general self-efficacy with a statistically significant bootstrapped standardised indirect effect path c: $a b=-0.02,95 \% \mathrm{BCa}$ CI $[-0.05,-0.001]$, with $R^{2}$ indicating that the model explains $5.8 \%$ of the variance in stress reactivity. This indicates that the negative effect of muscular strength on stressor reactivity can partly be explained via general self-efficacy. The effect size points towards a small mediation effect.

Within the second mediation model, a significant direct, inverse effect of self-perceived fitness on stressor reactivity was observed, path c': $b=-0.15, p=0.002,95 \% \mathrm{CI}$ $[-0.25,-0.05]$, and self-perceived fitness was significantly associated with general self-efficacy, path a: $b=0.24$, $p<0.001,95 \%$ CI $[0.11,0.36]$. General self-efficacy significantly predicted stressor reactivity, path $\mathrm{b}: b=-0.09$, $p=0.04,95 \%$ CI $[-0.18,-0.005]$. The bootstrapped indirect effect for self-efficacy was significant, path c: $a b=-0.02$. However, the confidence interval range contains zero, $95 \% \mathrm{BCa} \mathrm{CI}[-0.04,0.001]$. Therefore, there is no mediating effect of self-efficacy on the association between selfperceived fitness and resilience to stress.

\section{Discussion}

\section{Physical fitness predicts resilience to stress}

The main findings of this longitudinal study support the assumption of physical fitness to be a predictor of mental health and extend existing research by focussing on resilience to modern life stress as an outcome $[21,69,70]$. The results show that muscular and self-perceived fitness are positively associated with resilience to stress, indicated as low symptomatic stressor reactivity over several months.
Generally, the inverse association between muscular strength and mental health problems is in line with earlier investigations that target the predictive value of fitness for mental health resources, quality of life or the development of symptoms of depression and anxiety [14, 21, 22]. Still, until now there is only limited evidence for the specific effects of muscular and self-perceived fitness in relation to stress reactivity in natural settings [18, 21, 34, 71]. Ortega et al. [72] compared the predictive value of self-perceived fitness and objective measures of fitness, here CRF, concerning the risk for developing physical illness. They provided evidence that self-perceived fitness was a valid and reliable instrument to measure objective fitness, and that self-perceived fitness and cardiovascular disease prognosis are strongly associated.

Neither self-reported physical activity nor CRF predicted resilience to stress. The finding, that objective measures outperform habitual physical activity is in accordance with Baumeister et al. [73]. In a prospective, population-based study they showed that leisure-time, work- and sport-based physical activities were not significantly associated with common mental health disorders. Interestingly, objective fitness measures, here greater CRF, were associated with a lower incidence of depression and clinical anxiety. At the same time, the stress buffering, positive mental health effect of actual physical activity has been often reported. One explanation for the current finding could be that objectively assessed fitness provides a more stable health marker over time than self-reported physical activity. Particularly muscular strength may reliably mirror real participation in exercise and sports and therefore the state of the physiological system [74]. Even though self-reports, e.g., the physical activity questionnaire (IPAQ) capture a broad range of physical activities, self-report measures are often criticised to be subject to attentional biases or may rather fluctuate over time, depend on mood, or season [75, 76]. In addition, substantial discrepancies between subjective and objective (e.g., accelerometery) measures of physical activity, typically recording activity over a week, have previously been reported. Realtime measurement of activity and accelerometery may be a more accurate method for actual activity levels [75, 77]. Moreover, Lee et al. [78] compared data on physical activity levels and objective fitness measures. Herein, the described associations between activity and objective measures were gauged as poor and did not reach objective standards. Our results depict a similar picture, as the reported activity levels did not correlate with our objective fitness measures. Although we did not find a direct relationship between selfreported physical activities and fitness measures, regular health-related activities might, nonetheless, partly explain the positive link between fitness and resilience to stress. Therefore, future studies should still integrate measures on activity and fitness and examine whether the interplay between objectively measured physical activity (e.g., using 
accelerometers) and fitness together can predict resilience to stress and mental health.

With this study we could not replicate earlier findings of a positive association between CRF and mental health [20, 21] or between CRF and resilience to stress [34, 79]. On the one hand, the interpretation should consider that our sample depicts a rather low variance in the measure of maximal oxygen capacity. Up to $75 \%$ of the participants scored above the average [50], indicating an overall high performance on the test. This might partly be an explanation for the low predictive power of CRF for resilience outcomes in the longterm. For future studies it is necessary to include participants with larger variance in performance levels, including low, medium and high performers. On the other, preceding studies used self-assessed resilience rather than a stressornormalised resilience score which may also account the lack of a positive association between CRF or PA with resilience.

\section{Self-efficacy as a mediating mechanism}

To better clarify the still unresolved mechanisms underlying the beneficial effect of physical fitness on resilience, the mediating role of general self-efficacy expectations between fitness and resilience was analysed. Since, only muscular and self-perceived fitness were significantly related to resilience, we restricted mediation analyses to these two fitness components. Our hypothesis could be confirmed for muscular fitness, as the results showed that the relationship between muscular strength and resilience was partially mediated via general-self efficacy. Almost $20 \%$ of the variance within the effect of muscular fitness on resilience could be explained by self-efficacy expectations. However, for self-perceived fitness the mediation through self-efficacy did not reach significance, when introducing sex age and BMI as covariates. According to these findings, we assume that the positive effect of the actual (muscular) fitness levels is more likely to be explained by subsequent cognitive self-efficacy expectations. Though, the relationship between self-perceived fitness might work via different pathways. On a speculative note, another explanation could be that the perception of one's own fitness closely relates to the concept of selfefficacy and capability of acting. Therefore, these perceptions may share the same explaining variance which might partially eliminate the positive effect of self-efficacy and resilience to stress.

With mediation models we could verify evidence on the distinct associations between fitness and self-efficacy expectations on the one hand, and between self-efficacy and mental health on the other. Hereby, instead of fitness, previous studies mostly investigated the link between physical activity and self-efficacy [80,81]. In this context it is worth noting that since we introduced both measures at baseline assessment, it is difficult to clearly assert about the effect's direction. Utilising the social-cognitive theory by Bandura $[82,83]$ as a framework, activity levels and self-efficacy interact reciprocally. While physical activity has been found to contribute to heightened self-efficacy expectations, literature mostly supports the idea of self-efficacy to act positively on regular implementation and maintenance of activity or exercise participation [81, 84-86]. Only a few sports-related interventional studies have investigated self-efficacy as an outcome of sport involvement or exercise [87, 88]. Also in a recent review, sport scientists examined the potential mediating role of self-efficacy in the relationship between physical fitness and well-being. They could confirm that both fitness and self-efficacy play an important role for improved health, however, the causal relations remain unclarified [89]. This illustrates that more studies are needed to establish whether self-efficacy promotes physical activity or the other way around. Furthermore, we could show that higher self-efficacy was associated with lower reactivity to life events and daily stress, thus with proficient resilience outcomes. This is in line with earlier findings, demonstrating the beneficial effect of self-efficacy expectations on mental health and-in the context of positive appraisal style - on resilience to stress $[45,90,91]$. More specifically, this also confirms the potential stress buffering effect of self-efficacy in handling stressors and adversity, which was earlier tested in the context of daily stress, or traumatic events [41, 44, 92-94]. Altogether, the mediating effect of self-efficacy can be interpreted such as that higher levels of self-perceived and muscular fitness enforce one's self-efficacy or mastery experience.

In this current work we restrained our analyses to a single, partly explaining psychosocial mechanism in the fitness-resilience relationship, whereby a full mediation model could not be obtained. This underlines the complexity of this relationship and indicates that various mechanisms may be involved. To entirely reveal the pathways underlying the relationship between fitness and resilience, psychophysiological mechanisms should also be considered. For example, according to the "Cross-Stressor Adaptation hypothesis (CSA)" evidence exists for regular exercise blunting hormonal and metabolic stressor reactivity of the hypothalamic-pituitary-adrenal (HPA) axis, due to a biological adaptation process [95]. Herein, lower stressor reactivity and faster stress recovery may explain the beneficial effects of exercise on mental health [31, 96, 97]. As we found that fitness seems to come along with reduced stressor reactivity, represented by less mental health problems, our findings can be considered to be in line with the CSA hypothesis. Matching this, self-efficacy has also been shown to impact the neuro-endocrinological stress response and seems to be negatively related to symptoms of distress after psychosocial stress [98]. Elsewhere, the positive effects of exercise have also been attributed to a reduction of excessive inflammation through oxidative stress [99-101] or enhanced 
neuroplasticity and growth factor expression inducing structural changes in the brain [102-105]. Especially in the context of resilience to stress, the potential mediating mechanisms of fitness on mental health mostly remain unclarified and should be considered.

\section{Limitations and recommendations for future research}

Our results need to be interpreted in the light of several limitations. To the best of our knowledge, this present study is the first to investigate the association of physical fitness and stress reactivity in the form of mental health problems and, at the same time, to analyse the mediating role of selfefficacy on this relationship in a longitudinal study design. Therefore, it is difficult to compare the outcomes with earlier investigations that feature clear heterogeneity in methods and outcomes. In addition, for economic reasons, we opted for a composite score for muscular fitness, consisting of the well-validated hand strength test and the standing long jump. The standing long jump, as part of a fitness test battery, has already been applied in well-designed studies to capture physical fitness and health parameters $[55,106]$. However, it should be considered that the standing long jump has mainly been used and validated in adolescents and is less frequently used in adults. Hence, the results concerning the standing long jump should be interpreted with caution.

Furthermore, due to their personal demographic specifications, the sample comprised of mostly young, welleducated and healthy, individuals. As the participants could participate the fitness assessment on a voluntary basis, selfselection bias is conceivable, which may account for a nonsufficient variation in participants' fitness levels. Therefore, the results can hardly be generalised to individuals with low socioeconomic status as well as medical diagnoses and/or overweight. We recommend future studies to manage a greater differentiation in health status. Besides healthy individuals, considering clinical samples could increase generalizability and deliver distinguished information on psychologically burdened people. Conclusions regarding causality of the relationship between fitness and mediating self-efficacy are limited by the simultaneous assessment. In this respect, to be able to assert over the working direction, and changes over time due to fluctuations of the different measurements, we recommend methodological advanced cross-lagged panel designs, which could enable more insight into the reciprocal nature of physical activity, fitness, internal psychological resources, and mental health across time. From a methodological perspective, researchers and practitioners should be aware of the influence of stressor exposure when investigating the preventive effects of activity and fitness on mental health outcomes. From a preventive perspective, we cannot make a recommendation for specific intensities or durations of behavioural activations. However, the results allow for the recommendation of participation in physical activities that promote proficient muscular and selfperceived fitness. Since the maintenance of health-related activity over time may also depend on self-efficacy expectations [107], enhanced self-efficacy and mastery experience should play a considerable role in sport-based interventions for preventive purposes.

\section{Conclusion}

Altogether, we could show that muscular as well as selfperceived fitness can be viewed as independent, prognostic parameters in relation to resilience to stress over a timespan of several months. A psychological mechanism underlying the association between muscular fitness and stress resilience seems to comprise self-efficacy expectations. Therefore, our study supports the notion that fitness and resulting proficient self-efficacy expectations may have complementary benefits for the promotion of mental health.

Acknowledgements We gratefully acknowledge all participants who took part in the LORA study over the long-term. We appreciate the valuable help of the LORA study team from Frankfurt and Mainz and especially Victoria Anschütz, Alina Herrmann, Hannah Kurtz, Emily Mosel, Kristiyana Petrova, Charlotte Rabener, Sabrina Tenbuß, Ashley Timberlake, Judith Weinzierl and Nina von Werthern for performing the physical and psychological assessment as well as data collection.

Author contributions RJH was involved in the conception and design of the study, data acquisition, the analysis and interpretation of data, manuscript writing and final approval of the version to be submitted. SM, KFA and MMP were involved in the analysis and interpretation of data, revising and editing the article for important and intellectual content, and final approval. NG and DW were involved in the data acquisition, conception and design of the study and final approval and revision. BK was involved in revising the article for intellectual content, approval and the final version. AR, OT, RK, CJF, KL, AC, MW were involved in the conception and design of the study, revising and editing the article for important intellectual content, and final approval of the version to be submitted. All authors read and approved the final version of the manuscript.

Funding Open Access funding enabled and organized by Projekt DEAL. This study was supported by the German Research Foundation (DFG CRC 1193, subproject Z03, to KL and AR) and the EU (Horizon 2020 Framework Programme for Research and Innovation, under grant agreement no. 667303 [CoCA].

Data availability Data can be made available by the author upon request.

\section{Declarations}

Conflict of interest On behalf of all authors, the corresponding author states that there is no conflict of interest. 
Ethical approval All study procedures complied with the Code of Ethics of the World Medical Association (Declaration of Helsinki; Rickham, 2013) and were approved by the respective Ethics Committees in Mainz (registration number: 837.105.16(10424)) and Frankfurt am Main (registration number: 244/16), Germany.

Informed consent Before participation subjects provided written informed consent. All study procedures complied with the Code of Ethics of the World Medical Association (Declaration of Helsinki; Rickham, 2013) and were approved by the respective Ethics Committees in Mainz (registration number: 837.105.16(10424)) and Frankfurt am Main (registration number: 244/16), Germany.

Open Access This article is licensed under a Creative Commons Attribution 4.0 International License, which permits use, sharing, adaptation, distribution and reproduction in any medium or format, as long as you give appropriate credit to the original author(s) and the source, provide a link to the Creative Commons licence, and indicate if changes were made. The images or other third party material in this article are included in the article's Creative Commons licence, unless indicated otherwise in a credit line to the material. If material is not included in the article's Creative Commons licence and your intended use is not permitted by statutory regulation or exceeds the permitted use, you will need to obtain permission directly from the copyright holder. To view a copy of this licence, visit http://creativecommons.org/licenses/by/4.0/.

\section{References}

1. Trost SG, Blair SN, Khan KM (2014) Physical inactivity remains the greatest public health problem of the 21 st century: evidence, improved methods and solutions using the "7 investments that work" as a framework. Br J Sports Med 48(3):169-170. https:// doi.org/10.1136/bjsports-2013-093372

2. Guthold R, Stevens GA, Riley LM, Bull FC (2018) Worldwide trends in insufficient physical activity from 2001 to 2016: a pooled analysis of 358 population-based surveys with 1.9 million participants. Lancet Glob Heal 6:e1077-e1086. https://doi. org/10.1016/S2214-109X(18)30357-7

3. Trost SG, Blair SN, Khan KM (2014) Erratum: physical inactivity remains the greatest public health problem of the 21 st century: evidence, improved methods and solutions using the "7 investments that work" as a framework (British Journal of Sports Medicine (2014) 48 (169-70)). Br J Sports Med 48:401. https:// doi.org/10.1136/bjsports-2013-093372corr1

4. Hamer M, Endrighi R, Poole L (2012) Physical activity, stress reduction, and mood: insight into immunological mechanisms. Methods Mol Biol 934:89-102

5. Galper DI, Trivedi MH, Barlow CE et al (2006) Inverse association between physical inactivity and mental health in men and women. Med Sci Sports Exerc 38:173-178. https://doi.org/10. 1249/01.mss.0000180883.32116.28

6. Peluso MAM, Guerra de Andrade LHS (2005) Physical activity and mental health: the association between exercise and mood. Clinics (Sao Paulo). https://doi.org/10.1590/s1807-5932200500 0100012

7. Mammen G, Faulkner G (2013) Physical activity and the prevention of depression a systematic review of prospective studies. Am J Prev Med 45:649-657. https://doi.org/10.1016/j.amepre.2013. 08.001

8. Schuch FB, Vancampfort D, Firth J et al (2018) Physical activity and incident depression: a meta-analysis of prospective cohort studies. Am J Psychiatry. https://doi.org/10.1176/appi.ajp.2018. 17111194

9. Carek PJ, Laibstain SE, Carek SM (2011) Exercise for the treatment of depression and anxiety. Int J Psychiatry Med 41:15-28. https://doi.org/10.2190/pm.41.1.c

10. Stanton R, Happell B, Reaburn P (2014) The mental health benefits of regular physical activity, and its role in preventing future depressive illness. Nursing Res Rev. https://doi.org/10.2147/ NRR.S41956

11. Vandelanotte C, Geard D, Duncan MJ et al (2015) A meta-metaanalysis of the effect of physical activity on depression and anxiety in non-clinical adult populations. Health Psychol Rev 9:366-378. https://doi.org/10.1080/17437199.2015.1022901

12. Ströhle A (2009) Physical activity, exercise, depression and anxiety disorders. J Neural Transm. https://doi.org/10.1007/ s00702-008-0092-x

13. Bouchard C, Rankinen T, Timmons JA (2011) Genomics and genetics in the biology of adaptation to exercise. Compr Physiol 1:1603-1648. https://doi.org/10.1002/cphy.c100059

14. Evaristo S, Moreira C, Lopes L et al (2019) Muscular fitness and cardiorespiratory fitness are associated with health-related quality of life: results from labmed physical activity study. J Exerc Sci Fit 17:55-61. https://doi.org/10.1016/j.jesf.2019.01. 002

15. Ortega FB, Ruiz JR, Castillo MJ, Sjöström M (2008) Physical fitness in childhood and adolescence: a powerful marker of health. Int J Obes 32:1-11. https://doi.org/10.1038/sj.ijo.0803774

16. Salmon P (2001) Effects of physical exercise on anxiety, depression, and sensitivity to stress: a unifying theory. Clin Psychol Rev 21(1):33-61. https://doi.org/10.1016/s0272-7358(99)00032-x

17. Tacchi MJ, Heggelund J, Scott J (2019) Predictive validity of objective measures of physical fitness for the new onset of mental disorders in adolescents and young adults. Early Interv Psychiatry 13:1310-1318. https://doi.org/10.1111/eip.12783

18. Gerber M, Lindwall M, Lindegård A et al (2013) Cardiorespiratory fitness protects against stress-related symptoms of burnout and depression. Patient Educ Couns 93:146-152. https://doi.org/ 10.1016/j.pec.2013.03.021

19. Nilsson M, Kuhn HG, Nyberg J et al (2012) Cardiovascular fitness in males at age 18 and risk of serious depression in adulthood: Swedish prospective population-based study. Br J Psychiatry 201:352-359. https://doi.org/10.1192/bjp.bp.111.103416

20. Kandola A, Ashdown-Franks G, Stubbs B et al (2019) The association between cardiorespiratory fitness and the incidence of common mental health disorders: a systematic review and metaanalysis. J Affect Disord 257:748-757

21. Kettunen O, Kyröläinen H, Santtila M et al (2016) Greater levels of cardiorespiratory and muscular fitness are associated with low stress and high mental resources in normal but not overweight men. BMC Public Health 16:1-9. https://doi.org/10.1186/ s12889-016-3470-6

22. Marques A, Gomez-Baya D, Peralta M et al (2020) The effect of muscular strength on depression symptoms in adults: a systematic review and meta-analysis. Int J Environ Res Public Health 17:1-13. https://doi.org/10.3390/ijerph17165674

23. Volaklis K, Mamadjanov T, Meisinger C, Linseisen J (2019) Association between muscular strength and depressive symptoms: a narrative review. Wien Klin Wochenschr 131:255-264. https://doi.org/10.1007/s00508-019-1491-8

24. Fukumori N, Yamamoto Y, Takegami M et al (2015) Association between hand-grip strength and depressive symptoms: Locomotive Syndrome and Health Outcomes in Aizu Cohort Study (LOHAS). Age Ageing 44:592-598. https://doi.org/10.1093/ ageing/afv013

25. Avitsland A, Leibinger E, Haugen T et al (2020) The association between physical fitness and mental health in Norwegian 
adolescents. BMC Public Health 20:776. https://doi.org/10.1186/ s12889-020-08936-7

26. Amstadter AB, Myers JM, Kendler KS (2014) Psychiatric resilience: longitudinal twin study. Br J Psychiatry 205:275-280. https://doi.org/10.1192/bjp.bp.113.130906

27. Ioannidis K, Askelund AD, Kievit RA, Van Harmelen AL (2020) The complex neurobiology of resilient functioning after childhood maltreatment. BMC Med 18:1-16. https://doi.org/10.1186/ s12916-020-1490-7

28. Kalisch R, Baker D, Basten U et al (2019) The resilience framework as a strategy to combat stress-related disorders. nature.com. https://www.nature.com/articles/s41562-017-0200-8. Accessed 7 June 2019

29. Kalisch R, Köber G, Binder H et al (2021) The frequent stressor and mental health monitoring-paradigm: a proposal for the operationalization and measurement of resilience and the identification of resilience processes in longitudinal observational studies. Front Psychol. https://doi.org/10.3389/fpsyg. 2021.710493

30. Hegberg NJ, Tone EB (2015) Physical activity and stress resilience: considering those at-risk for developing mental health problems. Ment Health Phys Act 8:1-7. https://doi.org/10.1016/j. mhpa.2014.10.001

31. Rimmele U, Zellweger BC, Marti B et al (2007) Trained men show lower cortisol, heart rate and psychological responses to psychosocial stress compared with untrained men. Psychoneuroendocrinology 32:627-635. https://doi.org/10.1016/j.psyne uen.2007.04.005

32. Puterman E, Weiss J, Beauchamp MR et al (2017) Physical activity and negative affective reactivity in daily life. Health Psychol 36:1186-1194. https://doi.org/10.1037/hea0000532

33. Klaperski S, Seelig H, Fuchs R (2012) Sportaktivität als Stresspuffer [Physical activity as a stress buffer]. Zeitschrift fur Sportpsychologie 19(2):80-90. https://doi.org/10.1026/16125010/a000061

34. Schilling R, Herrmann C, Ludyga S et al (2020) Does cardiorespiratory fitness buffer stress reactivity and stress recovery in police officers? A real-life study. Front Psychiatry 11:1. https:// doi.org/10.3389/fpsyt.2020.00594

35. Bandura A (1989) Regulation of cognitive processes through perceived self-efficacy. Dev Psychol 25:729-735. https://doi.org/ 10.1037/0012-1649.25.5.729

36. Bandura A, Freeman W, Lightsey R (1999) Self-efficacy: The exercise of control. https://connect.springerpub.com/content/ sgrjcp/13/2/158.full.pdf. Accessed 4 Feb 2021

37. Bandura A (2010) Self-Efficacy. In: The Corsini Encyclopedia of Psychology. John Wiley \& Sons, Inc., Hoboken, NJ, USA. https://doi.org/10.1002/9780470479216.corpsy0836

38. Benight CC, Bandura A (2004) Social cognitive theory of posttraumatic recovery: the role of perceived self-efficacy. Behav Res Ther 42:1129-1148. https://doi.org/10.1016/j.brat.2003.08.008

39. Bisschop MI, Kriegsman DMW, Beekman ATF, Deeg DJH (2004) Chronic diseases and depression: the modifying role of psychosocial resources. Soc Sci Med 59:721-733. https://doi. org/10.1016/j.socscimed.2003.11.038

40. Bandura A, Caprara GV, Barbaranelli C et al (2003) Role of affective self-regulatory efficacy in diverse spheres of psychosocial functioning. Child Dev 74:769-782. https://doi.org/10.1111/ 1467-8624.00567

41. Maciejewski PK, Prigerson HG, Mazure CM (2000) Self-efficacy as a mediator between stressful life events and depressive symptoms. Differences based on history of prior depression. $\mathrm{Br}$ J Psychiatry 176:373-378. https://doi.org/10.1192/bjp.176.4.373

42. Rodriguez-Ayllon M, Cadenas-Sánchez C, Estévez-López F et al (2019) Role of physical activity and sedentary behavior in the mental health of preschoolers, children and adolescents: a systematic review and meta-analysis. Sport Med 49:1383-1410. https://doi.org/10.1007/s40279-019-01099-5

43. Sandin B, Sánchez-Arribas C, Chorot P, Valiente RM (2015) Anxiety sensitivity, catastrophic misinterpretations and panic self-efficacy in the prediction of panic disorder severity: towards a tripartite cognitive model of panic disorder. Behav Res Ther 67:30-40. https://doi.org/10.1016/j.brat.2015.01.005

44. Schueler K, Fritz J (2020) Psychological network analysis of general self-efficacy in high vs low resilient functioning healthy adults. OFC Preprints https://doi.org/10.31219/osf.io/kvgyj

45. Kalisch R, Müller MB, Tüscher O (2015) A conceptual framework for the neurobiological study of resilience. Behav Brain Sci 38:e92. https://doi.org/10.1017/S0140525X1400082X

46. Sonstroem RJ, Morgan WP (1989) Exercise and self-esteem: rationale and model. Med Sci Sports Exerc 21:329-337. https:// doi.org/10.1249/00005768-198906000-00018

47. McAuley E, Elavsky S, Motl RW, Konopack JF, Hu L, Marquez DX (2005) Physical activity, self-efficacy, and self-esteem: Longitudinal relationships in older adults. J Gerontol B Psychol Sci Soc Sci 60(5):268-275. https://doi.org/10.1093/geronb/60.5. P268

48. Chmitorz A, Neumann RJ, Kollmann B et al (2020) Longitudinal determination of resilience in humans to identify mechanisms of resilience to modern-life stressors: the longitudinal resilience assessment (LORA) study. Eur Arch Psychiatry Clin Neurosci. https://doi.org/10.1007/s00406-020-01159-2

49. ALPHA: Assessing Levels of PHysical Activity and fitness at population level. https://sites.google.com/site/alphaprojectphy sicalactivity/. Accessed 28 Mar 2019

50. Sykes K, Roberts A (2004) The Chester step test-a simple yet effective tool for the prediction of aerobic capacity. Physiotherapy 90:183-188. https://doi.org/10.1016/j.physio.2004.03.008

51. España-Romero V, Artero EG, Jimenez-Pavón D et al (2010) Assessing health-related fitness tests in the school setting: reliability, feasibility and safety; The ALPHA study. Int J Sports Med 31:490-497. https://doi.org/10.1055/s-0030-1251990

52. Bohannon RW (2015) Muscle strength. Curr Opin Clin Nutr Metab Care 18:465-470. https://doi.org/10.1097/MCO.00000 00000000202

53. Amaral JF, Mancini M, Novo Júnior JM (2012) Comparison of three hand dynamometers in relation to the accuracy and precision of the measurements. Braz J Phys Ther 16:216-224

54. Leblanc A, Taylor BA, Thompson PD et al (2015) Relationships between physical activity and muscular strength among healthy adults across the lifespan. Springerplus 4:557. https://doi.org/10. 1186/s40064-015-1357-0

55. Castro-Piñero J, Ortega FB, Artero EG et al (2010) Assessing muscular strength in youth: usefulness of standing long jump as a general index of muscular fitness. J Strength Cond Res 24:1810 1817. https://doi.org/10.1519/JSC.0b013e3181ddb03d

56. Padilla-Moledo C, Ruiz JR, Ortega FB et al (2012) Associations of muscular fitness with psychological positive health, health complaints, and health risk behaviors in Spanish children and adolescents. J Strength Cond Res 26:167-173. https://doi.org/ 10.1519/JSC.0b013e31821c2433

57. Ortega FB, Ruiz JR, España-Romero V et al (2011) The International Fitness Scale (IFIS): Usefulness of self-reported fitness in youth. Int J Epidemiol 40:701-711. https://doi.org/10.1093/ije/ dyr039

58. Craig CL, Marshall AL, Sjöström M et al (2003) International physical activity questionnaire: 12-Country reliability and validity. Med Sci Sports Exerc 35:1381-1395. https://doi.org/10.1249/ 01.MSS.0000078924.61453.FB

59. Helmerhorst HJ, Brage S, Warren J, Besson H, Ekelsund U (2012) A systematic review of reliability and objective criterion-related 
validity of physical activity questionnaires. Int J Behav Nutr Phys Act 9:103. https://doi.org/10.1186/1479-5868-9-103

60. Forde C (2018) Scoring the international physical activity questionnaire (IPAQ). University of Dublin. https://ugc.futurelearn. com/uploads/files/bc/c5/bcc53b14-ec1e-4d90-88e3-1568682f32 ae/IPAQ_PDF.pdf. Accessed 21 Mar 2019

61. Luszczynska A, Scholz U, Schwarzer R (2005) The general self-efficacy scale: multicultural validation studies. J Psychol 139:439-457. https://doi.org/10.3200/JRLP.139.5.439-457

62. Schwarzer RJM (1995) General Self-efficacy Scale (GES) https:// diabetes-psychologie.de/downloads/Beschreibung_GSE.pdf. Accessed 21 Mar 2019

63. Canli T, Qiu M, Omura K, Congdon E, Haas BW, Amin Z, Herrmann MJ, Constable RT, Lesch KP (2006) Neural correlates of epigenesis. Proc Natl Acad Sci USA 103(43):16033-16038

64. Chmitorz A, Kurth K, Mey LK et al (2019) Assessment of microstressors in adults: questionnaire development and ecological validation of the Mainz Inventory of Microstressors. JMIR Ment Heal 7:e14566. https://doi.org/10.2196/14566

65. Goldberg DP, Hillier VF (1979) A scaled version of the General Health Questionnaire. Psychol Med 9:139-145. https://doi.org/ 10.1017/s0033291700021644

66. Klaiberg A, Schumacher J, Brähler E (2004) General Health Questionnaire 28-statistical testing of a German version with a representative sample of the general population. Z Klin Psychol Psychiatr Psychother 52(1):31-42

67. Hayes AF (2017) Introduction to mediation, moderation, and conditional process analysis: a regression-based approach. Guilford publications

68. Davidson R, MacKinnon JG (1993) Estimation and inference in econometrics. OUP Catalogue. https://ideas.repec.org/b/oxp/ obooks/9780195060119.html. Accessed 13 Mar 2021

69. Gerber M, Pühse U (2009) Review article: do exercise and fitness protect against stress-induced health complaints? A review of the literature. Scand J Public Health 37:801-819. https://doi.org/10. $1177 / 1403494809350522$

70. Fuchs R, Klaperski S (2018) Stressregulation durch Sport und Bewegung. In: Handbuch Stressregulation und Sport. Springer Berlin Heidelberg, pp 205-226. https://doi.org/10.1007/ 978-3-662-49322-9_9

71. Gerber M, Fuchs R (2018) Stressregulation und Sport: Ein Überblick zum Stand der Forschung. In: Handbuch Stressregulation und Sport. Springer Berlin Heidelberg, pp 3-20. https://doi.org/ 10.1007/978-3-662-49322-9_26

72. Ortega FB, Sánchez-López M, Solera-Martínez M et al (2013) Self-reported and measured cardiorespiratory fitness similarly predict cardiovascular disease risk in young adults. Scand J Med Sci Sport 23:749-757. https://doi.org/10.1111/j.1600-0838.2012. 01454.x

73. Baumeister SE, Leitzmann MF, Bahls M et al (2017) Associations of leisure-time and occupational physical activity and cardiorespiratory fitness with incident and recurrent major depressive disorder, depressive symptoms, and incident anxiety in a general population. J Clin Psychiatry 78:e41-e47. https://doi. org/10.4088/JCP.15m10474

74. Blair SN, Cheng Y, Scott Holder J (2001) Is physical activity or physical fitness more important in defining health benefits? In: Medicine and Science in Sports and Exercise. American College of Sports Medicine. https://doi.org/10.1097/00005768-20010 6001-00007

75. Prince SA, Adamo KB, Hamel ME et al (2008) A comparison of direct versus self-report measures for assessing physical activity in adults: a systematic review. Int J Behav Nutr Phys Act. https:// doi.org/10.1186/1479-5868-5-56

76. Fogelholm M, Malmberg J, Suni J et al (2006) International physical activity questionnaire: validity against fitness. Med Sci
Sports Exerc 38:753-760. https://doi.org/10.1249/01.mss.00001 94075.16960.20

77. Adamo KB, Prince SA, Tricco AC et al (2009) A comparison of indirect versus direct measures for assessing physical activity in the pediatric population: a systematic review. Int J Pediatr Obes 4:2-27. https://doi.org/10.1080/17477160802315010

78. Lee PH, Macfarlane DJ, Lam TH, Stewart SM (2011) Validity of the international physical activity questionnaire short form (IPAQ-SF): a systematic review. Int J Behav Nutr Phys Act 8:115. https://doi.org/10.1186/1479-5868-8-115

79. Schilling R, Colledge F, Ludyga S et al (2019) Does cardiorespiratory fitness moderate the association between occupational stress, cardiovascular risk, and mental health in police officers? Int J Environ Res Public Health 16:2349. https://doi.org/10.3390/ ijerph16132349

80. McAuley E, Blissmer B, Katula J et al (2000) Physical activity, self-esteem, and self-efficacy relationships in older adults: a randomized controlled trial. Ann Behav Med 22:131-139. https:// doi.org/10.1007/BF02895777

81. Maher J, Doerksen S, Elavsky S et al (2013) A daily analysis of physical activity and satisfaction with life in emerging adults. psycnet.apa.org. https://doi.org/10.1037/a0030129

82. Dzewaltowski DA (1994) Physical activity determinants: a social cognitive approach. Med Sci Sports Exerc 26:1395-1399. https:// doi.org/10.1249/00005768-199411000-00015

83. Beauchamp MR, Crawford KL, Jackson B (2019) Social cognitive theory and physical activity: mechanisms of behavior change, critique, and legacy. Psychol Sport Exerc 42:110-117. https://doi.org/10.1016/j.psychsport.2018.11.009

84. Penedo FJ, Dahn JR (2005) Exercise and well-being: a review of mental and physical health benefits associated with physical activity. Curr Opin Psychiatry 18:189-193. https://doi.org/10. 1097/00001504-200503000-00013

85. Warner LM, Schüz B, Wolff JK et al (2014) Sources of self-efficacy for physical activity. Heal Psychol 33:1298-1308. https:// doi.org/10.1037/hea0000085

86. Schwarzer R, Schüz B, Ziegelmann JP, Lippke S, Luszczynska A, Scholz U (2007) Adoption and maintenance of four health behaviors: theory-guided longitudinal studies on dental flossing, seat belt use, dietary behavior, and physical activity. Ann Behav Med 33(2):156-166. https://doi.org/10.1007/BF02879897

87. Martin EC, Dick AM, Scioli-Salter ER, Mitchell KS (2015) Impact of a yoga intervention on physical activity, self-efficacy, and motivation in women with PTSD symptoms. J Altern Complement Med 21(6):327-332

88. McAuley E, Szabo A, Gothe N, Olson EA (2011) Self-efficacy: implications for physical activity, function, and functional limitations in older adults. Am J Lifestyle Med 5:361-369. https://doi. org/10.1177/1559827610392704

89. Medrano-Ureña MDR, Ortega-Ruiz R, Benítez-Sillero JDD (2020) Physical fitness, exercise self-efficacy, and quality of life in adulthood: a systematic review. Int J Environ Res Public Health 17(17):6343. https://doi.org/10.3390/ijerph17176343

90. Montpetit MA, Bergeman CS (2007) Dimensions of control: mediational analyses of the stress-health relationship. Pers Individ Dif 43:2237-2248. https://doi.org/10.1016/j.paid.2007.07. 003

91. Teicher MH, Parigger A (2015) The 'maltreatment and abuse chronology of exposure' (mace) scale for the retrospective assessment of abuse and neglect during development. PLoS ONE 10:e0117423. https://doi.org/10.1371/journal.pone.0117423

92. Gallagher MW, Long LJ, Phillips CA (2020) Hope, optimism, self-efficacy, and posttraumatic stress disorder: a meta-analytic review of the protective effects of positive expectancies. J Clin Psychol 76:329-355. https://doi.org/10.1002/jclp.22882 
93. Schönfeld P, Preusser F, Margraf J (2017) Costs and benefits of self-efficacy: differences of the stress response and clinical implications. Neurosci Biobehav Rev 75:40-52. https://doi.org/ 10.1016/j.neubiorev.2017.01.031

94. Schönfeld P, Brailovskaia J, Zhang XC, Margraf J (2019) Selfefficacy as a mechanism linking daily stress to mental health in students: a three-wave cross-lagged study. Psychol Rep 122:2074-2095. https://doi.org/10.1177/0033294118787496

95. Sothmann M (2006) The Cross-Stressor Adaptation Hypothesis and Exercise Training. https://psycnet.apa.org/record/200602237-010. Accessed 15 Nov 2019

96. Tsatsoulis A, Fountoulakis S (2006) The protective role of exercise on stress system dysregulation and comorbidities. In: Annals of the New York Academy of Sciences. Blackwell Publishing Inc., pp 196-213. https://doi.org/10.1196/annals.1367.020

97. Traustadóttir T, Bosch PR, Cantu T, Matt KS (2004) Hypothalamic-pituitary-adrenal axis response and recovery from highintensity exercise in women: effects of aging and fitness. J Clin Endocrinol Metab 89:3248-3254. https://doi.org/10.1210/jc. 2003-031713

98. Nierop A, Wirtz PH, Bratsikas A et al (2008) Stress-buffering effects of psychosocial resources on physiological and psychological stress response in pregnant women. Biol Psychol 78:261268. https://doi.org/10.1016/j.biopsycho.2008.03.012

99. Eyre HA, Papps E, Baune BT (2013) Treating depression and depression-like behavior with physical activity: an immune perspective. Front Psychiatry 4:3. https://doi.org/10.3389/fpsyt. 2013.00003

100. Palmefors H, DuttaRoy S, Rundqvist B, Börjesson M (2014) The effect of physical activity or exercise on key biomarkers in atherosclerosis - a systematic review. Atherosclerosis 235:150 161. https://doi.org/10.1016/j.atherosclerosis.2014.04.026

101. Ploeger HE, Takken T, de Greef MH, Timmons BW (2009) The effects of acute and chronic exercise on inflammatory disease: a systematic review. Exerc Immunol Rev 15:6-41

102. Erickson KI, Leckie RL, Weinstein AM (2014) Physical activity, fitness, and gray matter volume. Neurobiol Aging. https://doi.org/ 10.1016/j.neurobiolaging.2014.03.034

103. Hayes SM, Hayes JP, Cadden M, Verfaellie M (2013) A review of cardiorespiratory fitness-related neuroplasticity in the aging brain. Front Aging Neurosci 5:31. https://doi.org/10.3389/fnagi. 2013.00031

104. Vaynman S, Ying Z, Gomez-Pinilla F (2004) Hippocampal BDNF mediates the efficacy of exercise on synaptic plasticity and cognition. Eur J Neurosci 20:2580-2590. https://doi.org/10. 1111/j.1460-9568.2004.03720.x

105. Zoladz JA, Pilc A (2010) The effect of physical activity on the brain derived neurotrophic factor: from animal to human studies. J Physiol Pharmacol 61:533-541

106. Vancampfort D, Probst M, Sweers K et al (2012) Eurofit test battery in patients with schizophrenia or schizoaffective disorder: reliability and clinical correlates. Eur Psychiatry 27:416-421. https://doi.org/10.1016/j.eurpsy.2011.01.009

107. Dishman RK, McIver KL, Dowda M, Saunders RP, Pate RR (2019) Self-efficacy, beliefs, and goals: moderation of declining physical activity during adolescence. Health Psychol 38(6):483. https://doi.org/10.1037/hea0000734 